\title{
Compact Metamaterial-Based Tunable Zeroth-Order Resonant Antenna with Chip Variable Capacitor
}

\author{
Youn-Kwon Jung · Bomson Lee*
}

\begin{abstract}
This letter presents a compact metamaterial-based tunable zeroth-order resonant antenna. It is based on the double-negative unit cell with a function of tunable inductance realized by a varactor and impedance convertor in the shunt branch. The resonant frequency of the designed antenna ranges from 2.31 to $3.08 \mathrm{GHz}$, depending on the capacitance of the used varactor. Its size is very compact $\left(0.05 \lambda_{0} \times 0.2 \lambda_{0}\right)$ with a relatively wide tunable range of $29.1 \%$. The impedance bandwidth of the antenna is from 20 to $50 \mathrm{MHz}$ for the resonant center frequency. The measured maximum total realized gain is from $-0.68 \mathrm{dBi}(2.43 \mathrm{GHz})$ to $1.69 \mathrm{dBi}(2.97 \mathrm{GHz})$. The EM-simulated and measured results are in good agreement.
\end{abstract}

Key Words: Metamaterials, Negative Refractive Index, Small Antenna, Zeroth-Order Antenna.

\section{Introduction}

Recently, there is a concentrated research effort on the applications using the metamaterial-based transmission lines (MTM-TLs)-or right/left-handed transmission line (RLH-TL)-such as leaky-wave antennas, couplers, phase shifters, etc. [1]. A zeroth-order resonant (ZOR) antenna is one of the important applications of the MTM because it can be designed to be very compact. However, a disadvantage of the ZOR antenna is its narrow operating bandwidth. On the other hand, recent antennas for present day wireless communication require a compact size and wideband property for the transfer of a huge amount of information. In [2], a wideband epsilon negative (ENG) ZOR antenna using a mushroom structure was presented at an operating frequency of $9.2 \mathrm{GHz}$. It has relatively wide bandwidth of about $20 \%$. The mushroom structures cannot be used for commercial services in the frequency range between $700 \mathrm{MHz}$ to $3 \mathrm{GHz}$ since it has very small shunt inductance. In [3], a miniaturized ENG ZOR patch antenna with an improved bandwidth was proposed. The miniaturization and broad bandwidth of the antenna is achieved by using a meandered via and a high permeability substrate. A tunable internal antenna with an ENG ZOR property has been presented for the digital video broadcasting-handheld service with a tuning range from 474 to $702 \mathrm{MHz}$ [4]. The size of the antenna is very compact, but its voltage standing wave ratio (VSWR) is large (about 2 to 4.5). In this letter, an open-terminated tunable double-negative (DNG) ZOR antenna at 2.3 to $3.1 \mathrm{GHz}$ with a very compact size and small VSWR is proposed using a varactor. The required shunt inductance is realized using a stub and varactor. Its performances are evaluated in terms of dispersion curves, reflection coefficients, and radiation patterns.

\section{Design of Proposed Antenna}

Fig. 1 shows the equivalent circuit of an asymmetric 1-D MTM-TL unit cell. The unit cell has been modified from a symmetric shape [5] in order to facilitate open (or short) termination for resonant antenna applications. The unit cell of the MTM line usually consists of a series capacitor with $C_{0}$, shunt inductor with $L_{0}$, and conventional transmission line (RH-TL) section with an electrical length of $k d$. The RH-TL is characterized by the series inductance $L d$ and shunt capacitance $C d$. The ZOR has been extensively analyzed and its design equations have been provided in [6]. Fig. 2(a) and (b) show the equivalent circuit of the tunable DNG MTM-TL unit cell and its dispersion curves for different values of the bias voltages $V_{\text {Bias }}$. The shunt inductance $L_{0}$ is replaced with a variable capacitor and a section of stub to pro-

Manuscript received April 9, 2013 ; Revised May 9, 2013 ; Accepted August 13, 2013. (ID No. 20130409-012J)

Dept. of Electronics and Radio Engineering, College of Electronics and Information, Kyung Hee University, Tongin, Korea.

${ }^{*}$ Corresponding Author : Bomson Lee (e-mail : bomson@khu.ac.kr)

This is an Open-Access article distributed under the terms of the Creative Commons Attribution Non-Commercial License (http://creativecommons.org/licenses/ by-nc/3.0) which permits unrestricted non-commercial use, distribution, and reproduction in any medium, provided the original work is properly cited. 
vide a tuning operation of the MTM-TL. The characteristic impedance $Z_{s}$ of the stub has been chosen to be $100 \Omega$ (line width $=1.3 \mathrm{~mm}$ ) to ensure that the stub line width is adequate for the connection to the main line. Its electrical length has been optimized to be $58^{\circ}$ at $3 \mathrm{GHz}$ for a wide tuning range and compact design. The SMV1405 (Skyworks Solution Inc.) plastic packaged abrupt junction varactor diode has been selected to control the $C_{\mathrm{v}}$ values. The recommended capacitance range of the varactor is from 2.67 to $0.63 \mathrm{pF}$ with the necessary reverse bias voltages from 0 to $30 \mathrm{~V}$. The used varactor model in the simulations is the lumped series $\mathrm{RC}$ circuit with $R=0.8 \Omega$ and recommended capacitances. We restrict the use of the $C_{v}$ values from $2.67 \mathrm{pF}$ (about $0 \mathrm{~V}$ ) to $0.7 \mathrm{pF}$ (about $25 \mathrm{~V}$ ). For this range, the tuned $L_{0}$ which is determined by (1) is from $5.64 \mathrm{nH}$ to about $2 \mathrm{nH}$ at $3 \mathrm{GHz}$.

$$
Z_{\text {in, converter }}=Z_{s} \cdot \frac{1 / j \omega C_{v}+j \cdot Z_{s} \cdot \tan \beta l}{Z_{s}+j \cdot 1 / j \omega C_{v} \cdot \tan \beta l} \approx j \omega L_{0}
$$

Using [5], the determined design value of $C_{0}$ is $2 \mathrm{pF}$ at $3 \mathrm{GHz}$. In Fig. 2(b), the dispersion curves for $\beta d$ are

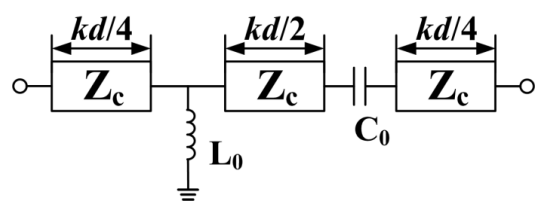

Fig. 1. Equivalent circuit of a metamaterial-based transmission line unit cell.

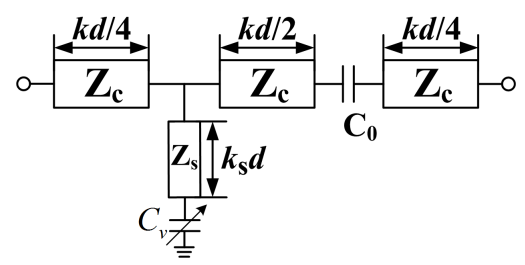

(a)

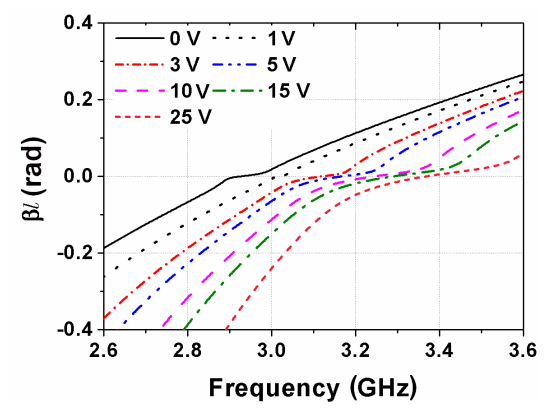

(b)

Fig. 2. Tunable metamaterial-based transmission line unit cell with varactor: (a) equivalent circuit and (b) dispersion curves.

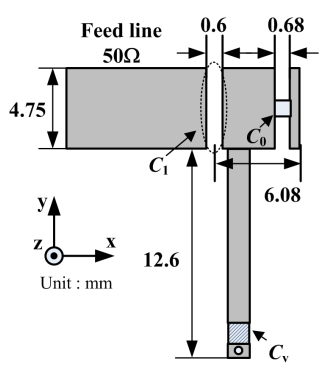

(a)

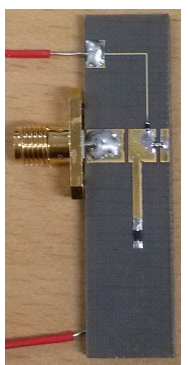

(b)

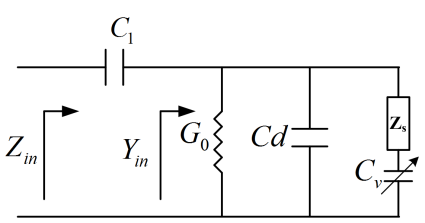

(c)

Fig. 3. Tunable double-negative zeroth-order resonant antenna: (a) schematic, (b) fabricated antenna, and (c) equivalent circuit.

shown to cross zero between 2.9 and $3.4 \mathrm{GHz}$. The name of the ZOR antenna comes from the property of $\beta d=0$. Due to the tuning of $L_{0}$, the line becomes somewhat unbalanced. For the antenna applications with one unit cell, that effect is not serious, or even negligible, in the used frequency band. Fig. 3(a) and (b) show the proposed structure of the open-terminated tunable DNG ZOR antenna with impedance convertor, designed on a microstrip line and fabricated antenna, respectively. Its equivalent circuit can be simplified as shown in Fig. 3(c). The antenna substrate is a Tefron $\left(\varepsilon_{r}=2.2\right.$, hei$\mathrm{ght}=1.6 \mathrm{~mm})$. The ground plane size is $12 \mathrm{~mm} \times 60 \mathrm{~mm}$. The antenna size is very compact $(6 \mathrm{~mm} \times 17.4 \mathrm{~mm}, 0.05$ $\lambda_{0} \times 0.2 \lambda_{0}$ ). The antenna consists of the RH line with electrical length $k d$ of $30^{\circ}$, a series capacitor with $C_{0}$, impedance convertor, and coupling capacitor $C_{1}$. With the use of the coupling capacitor, the resonant frequency of the antenna shifts somewhat downward [6]. The DC bias feeding line in Fig. 3(b) is designed to effectively protect the radio frequency $(\mathrm{RF})$ line from the bias line at resonant frequencies with the open-ended TL with $200 \Omega$ (the thinnest possible), and a resistor with $5 \mathrm{M} \Omega$. It means that the bias line seems to be an open circuit at resonant frequencies. The spacing between the RF line and the bias source point has been chosen to be 10 $\mathrm{mm}$ for reduced coupling between the line and RF line. It means that the radiation patterns are not influenced by the bias line.

\section{Performance Evaluations}

The $\left|S_{11}\right|$ 's of the antenna versus frequency for differ- 


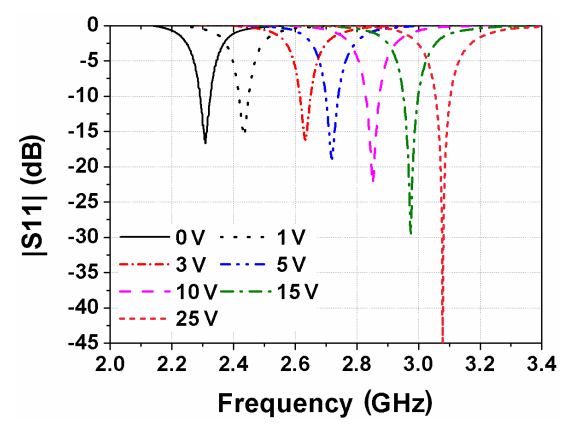

Fig. 4. Measured $\left|S_{11}\right|$ for different bias voltages.

ent bias voltages are shown in Fig. 4. The resonant frequency of the antenna sweeps between 3.08 and 2.31 $\mathrm{GHz}$ by changing the capacitance of the varactor using the DC bias voltage from 0 to $25 \mathrm{~V}$. The tunable frequency range is about $29 \%$. The maximum and minimum $10 \mathrm{~dB}$ bandwidth of the antenna are $50 \mathrm{MHz}$ (at $3.08 \mathrm{GHz}$ ) and $20 \mathrm{MHz}$ (at $2.31 \mathrm{GHz}$ ), respectively. The maximum bias voltage of the varactor may further be decreased depending on the chip varactors. Fig. 5 shows the EM-simulated and measured gain patterns of the ZOR antenna at $2.31 \mathrm{GHz}$ in the $\mathrm{YZ}$ plane. When $C_{v}=2.67 \mathrm{pF}\left(V_{\text {bias }}=0 \mathrm{~V}\right)$, the measured maximum gain of the antenna is $1.58 \mathrm{dBi}$. The EM-simulated gains are shown to reasonably agree with the measured ones. Fig. 6 (a) and (b) shows the measured $E_{\theta}$ and $E_{\phi}$ gains of the fabricated antenna for difference values of the bias voltages in YZ plane. The gains of the antenna may further be increased depending on the fabrication technology of the chip varactors.

\section{Conclusions}

A tunable DNG ZOR antenna using a varactor and transmission line impedance convertor has been designed at around $2.4 \mathrm{GHz}$. The resonant frequency of the antenna can be controlled conveniently with one voltage source. The size of the antenna is only $6 \mathrm{~mm} \times 17.4 \mathrm{~mm}$ $\left(0.05 \lambda_{0} \times 0.2 \lambda_{0}\right)$. The EM-simulated and measured tu-

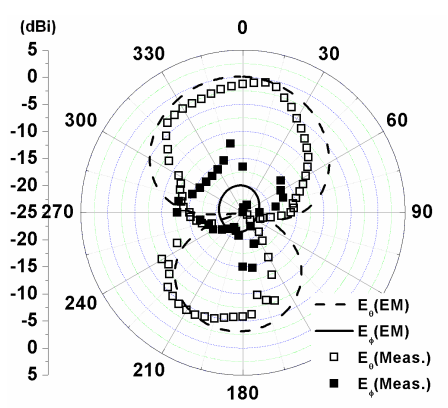

Fig. 5. EM-simulated and measured gain patterns of the antenna at $2.31 \mathrm{GHz}$ (YZ plane).

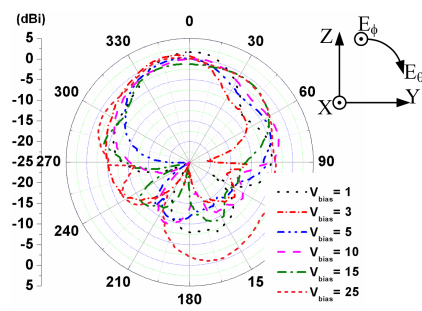

(a)

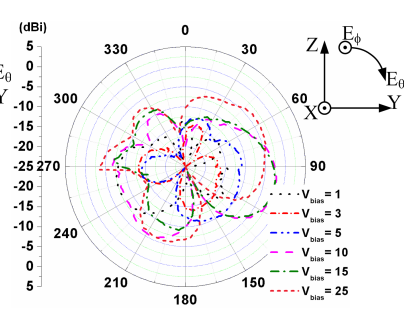

(b)
Fig. 6. Measured gain patterns of the antenna for difference values of the bias voltages in the YZ plane: (a) $E_{\theta}$ (elevation plain) and (b) $E_{\phi}$ (azimuth plain).

nable range is about $700 \mathrm{MHz}$ with a $10 \mathrm{~dB}$ return loss bandwidth of $20 \mathrm{MHz}$ to $50 \mathrm{MHz}$ at the center resonant frequency.

The EM-simulated and measured antenna gain patterns are in reasonable agreement. The measured gains are from $-0.68 \mathrm{dBi}(2.43 \mathrm{GHz})$ to $1.69 \mathrm{dBi}(2.97 \mathrm{GHz})$. Due to its small size and simple structure, the proposed antenna is a very attractive candidate for the commercial wireless communication services.

This work was supported by the National Research Foundation of Korea grant funded by the Korea government (No. 2013015202).

\section{References}

[1] G. V. Eleftheriades and K. G. Balmain, Negative Refraction Metamaterials: Fundamental Principles and Applications. Hoboken, NJ: John Wiley \& Sons, 2005.

[2] W. C. Chang and B. Lee, "Wideband one-unit-cell ENG zeroth-order resonant antenna," IET Electronics Letters, vol. 45, no. 25, pp. 1289-1291, Dec. 2009.

[3] S. T. Ko and J. H. Lee, "Miniaturized broadband ENG ZOR antenna using a high permeability substrate," Journal of the Korea Electromagnetic Engineering Society, vol. 11, no. 3, pp. 201-206, Sep. 2011.

[4] J. Kim, G. Kim, W. Seong, and J. Choi, "A tunable internal antenna with an epsilon negative zeroth order resonator for DVB-H service," IEEE Transactions on Antennas and Propagation, vol. 57, no. 12, pp. 4014-4017, Dec. 2009.

[5] C. Choi, K. Jun, and B. Lee, "Investigation of radiation effects for 1-D left handed transmission lines," in Proceedings of the IEEE Antennas and Propagation Society International Symposium, San Diego, CA, 2008.

[6] T. G. Kim and B. Lee, "Metamaterial-based compact zeroth-order resonant antenna," IET Electronics Letters, vol. 45, no. 1, pp. 12-13, Jan. 2009. 